\title{
Mudança Tecnológica, Estrutura Ocupacional e Distribuição de Renda no Longo Prazo: a contribuição de Carlota Perez e o Paradigma Tecno-Economico Atual
}

\author{
Victo José da Silva Neto, Universidade Estadual de Campinas
}

\section{Resumo}

O objetivo deste artigo é discutir a visão pereziana de como a distribuição de renda e a estrutura ocupacional interagem com os padrões de inovação e de organização da atividade econômica sob a influência de um paradigma tecno-econômico (PTE). Recuperamos a trajetória de construção do arcabouço do PTE e enfatizamos sua filiação kuznetsiana. Identificamos, ao longo da construção do PTE, duas abordagens para a distribuição da renda e seu papel na dinâmica do PTE: a abordagem (i) estruturante enfatiza a estrutura ocupacional, seu consequente padrão de distribuição de renda e a trajetória tecnológica/institucional daí resultante; a abordagem da (ii) desigualdade pendular, conceitualiza a distribuição de renda como um vetor da saturação de mercados e da exacerbação dos conflitos sociais. O comportamento pendular para a distribuição de renda (que evoluiria de acordo com a fase do PTE) - deriva de um papel disruptivo e funcional para a concentração: forçar a recomposição institucional. Finalmente, lançamos mão de dados preliminares sobre a estrutura ocupacional e distributiva nos EUA (séries temporais da World Inequality Database e do World Inequality Report) para levantar possíveis explicações para a manutenção da tendência concentradora de renda - mesmo após o advento das crises financeiras que deveriam ter movido o pêndulo da desigualdade na direção de uma prosperidade compartilhada.

Palavras-chave: paradigma tecno-econômico; estruura ocupacional; distribuição de renda

Área ABEIN: 5.5 - Inovação e mudanças técnica, organizacional e institucional - Mudanças técnicas, organizações e instituições JEL: O30

\begin{abstract}
The aim of this paper is to discuss the perezian view of how income distribution and occupational structure interact with the patterns of innovation and organization of economic activity under the influence of a techno-economic paradigm (TEP). We have recovered the construction path of the TEP framework and emphasized its Kuznetsian affiliation. Throughout the TEP construction, we have identified two approaches to income distribution and their role in TEP dynamics: the structuring approach (i) emphasizes the occupational structure, its consequent pattern of income distribution, and the resulting technological/institutional trajectory ; the (ii) pendular inequality approach conceptualizes income distribution as a vector of market saturation and exacerbation of social conflicts. The pendular behavior for income distribution (which would evolve accordingly to the TEP phase) - is derived from a disruptive and functional role for the concentration: to force the institutional recomposition. Finally, we gathered preliminary data on the occupational and distributive structure for the USA (World Inequality Database and the World Inequality Report) to raise possible explanations for the unchanged income-concentrating trend - even after the advent of the financial crises that should have moved the pendulum of inequality toward shared prosperity.
\end{abstract}

Key-words: techno-economic paradigm; occupational structure; income distribution 


\section{Introdução}

"A desigualdade não funciona e as pessoas não gostam dela" (BOWLES, 2010:xiii, tradução nossa). Desta forma, S. Bowles resume a visão da nova economia da desigualdade, um corpo de literatura que tem tomado forma nos últimos anos. O estudo da desigualdade como meio para atingir o desenvolvimento sócio-econômico é conjugado com o estudo da desigualdade como obstáculo ao crescimento econômico, à produtividade e à inovação. Entre as questões levantadas estão: como a desigualdade de renda e/ou riqueza afeta o crescimento econômico baseado no progresso técnico ${ }^{1}$ ? Como a desigualdade afeta a produtividade potencial?

Esta busca por conectar os pólos da distribuição e da produtividade está presente nos debates promovidos por instituições influentes no debate econômico:"equality is also a prerequisite for progress with a development model that focuses on innovation and learning that have a positive effect on productivity" (CEPAL, 2018:5). E ainda, "Equality is a necessary condition for the dynamic efficiency of the economy in that it creates a framework of institutions, policies and efforts that place the highest priority on innovation and capacity-building" (CEPAL, 2018:7). Estariamos vivendo em uma economia de brutal desigualdade e rent-seeking em que as inovações são desencorajadas pela paradoxal combinação de lucros corporativos recordes e investimentos em baixa (UNCTAD, 2018:4).

Na economia da inovação, haverá alguma iniciativa semelhante? Algum estudo na linha dos apresentados acima, que enfatizam a importância da distribuição na conformação de um ambiente inovativo? Há uma longa tradição nos estudos de economia da inovação de privilegiar o lado da oferta e negligenciar a interação entre a estrutura da demanda/ocupacional e distribuição de renda com o padrão de inovação. Neste ensaio pretendemos recuperar ao menos uma linha dentro da tradição da economia da inovação e do progresso tecnológico que tocou nestas questões: a visão de ondas longas de desenvolvimento baseadas em paradigmas tecno-econômicos (PEREZ 1983; FREEMAN e PEREZ, 1988; TYLECOTE, 1992; FREEMAN e LOUÇA, 2001; PEREZ, 2002; DRECHSLER et. al, 2009). Concordamos com Schot e Kanger (2018:1047) que a versão pereziana do PTE é a mais completa e promissora dentre todas. Além disto, Perez aborda - de formas diferentes ao longo do tempo - as conexões entre o progresso técnico, a estrutura ocupacional e a distribuição de renda, que queremos explorar.

O objetivo deste artigo é discutir a visão pereziana de como a distribuição de renda e a estrutura ocupacional interagem com os padrões de inovação e de organização da atividade econômica sob a influência de um paradigma tecno-econômico. Entendemos que a proposta pereziana pode ser um ponto de partida para avançar na compreensão desta relação usualmente negligenciada. Começamos apresentando o PTE como um desdobramento das ideias de Simon Kuznets. Em seguida, comparamos as duas abordagens dadas à distribuição de renda ao longo da trajetória de construção deste arcabouço. Finalmente, levantamos dados e séries temporais de longo prazo referente a desigualdade de renda e riqueza nos EUA nos séculos XX/XXI e esboçamos uma explicação tentativa sobre a natureza do PTE contemporâneo e sua relação com a estrutura ocupacional/distributiva atual.

\footnotetext{
1 "[...] societies with greater inequality are less liquely to make public investments which enhance productivity, such as in public transportation, infrastructure, technology and education" (STIGLITZ, 2016)
} 


\section{Parte I - Paradigmas Tecno-Econômicos: Um arcabouço kuznetsiano}

Carlota Perez propõe o conceito de paradigmas tecnoeconômicos (PTE) pela primeira vez em 1983. Neste trabalho ela prefere chamá-los de estilos tecnológicos (technological styles) (PEREZ, 1983). Além de desenvolver os elementos conceituais do PTE, ela aplica seu esquema analítico no que teria sido o quarto ciclo - de produção em massa, baseado nos princípios de organização taylorista-fordista. Dois anos depois (PEREZ, 1985), ela aplica o mesmo arcabouço no que estava por vir: o desenvolvimento do quinto ciclo baseado na microeletrônica.

A autora afirma que a interpretação do mecanismo cíclico do capitalismo colocada em seu artigo procura compreender as depressões que ocorrem de forma aproximadamente regular na história do capitalismo e também quais seriam os mecanismos que fazem com que inovações tecnológicas agrupadas se desdobrem em ciclos longos de expansão dos negócios e, portanto, em crescimento econômico² (PEREZ, 1983). Na década de 1980, contudo, o arcabouço ainda estava em construção. Perez ainda não havia associado explicitamente a mudança do paradigma com o papel das finanças, o que ocorreria em sua principal obra, Technological Revolutions and Financial Capital (doravante TRFC). Mesmo assim, as idéias centrais do PTE consolidaram-se nesta época (PEREZ, 1983; 1985; FREEMAN e PEREZ, 1988). A figura 1 esquematiza a visão da autora que já está contida em sua primeira proposição do conceito.

Ela divide o capitalismo em dois sub-sistemas: o tecno-econômico e o sócioinstitucional. Fases de crescimento e expansão econômica ocorreriam quando os dois subsistemas estão em harmonia. Estar em harmonia significa que as instituições seriam compatíveis e suportivas de um modelo de negócios baseado no estilo tecnológico derivado do sub-sistema tecno-econômico corrente. Transcorrido certo tempo, haveria um limite inerente ao PTE. A gradual corrosão dos ganhos levaria a "introdução" de um novo estilo tecnológico que exigiria novas instituições. Em Perez (1983) não há alusão a quem introduziria este novo estilo tecnológico ou de onde ele vêm ${ }^{3}$. Chama atenção a visão de que haveriam limites inerentes às tecnologias de serem exploradas economicamente.

Apesar das ideias de Perez serem associadas ao renascimento do pensamento schumpeteriano (KATTEL et al, 2009), Simon Kuznets talvez tenha enfatizado com maior veemência a exaustão de ciclos tecnológicos do que Schumpeter (1939) - e antecipado em boa parte a perspectiva do PTE. A visão de Schumpeter do comportamento cíclico sempre incluiu uma tendência para o retorno ao equilíbrio (com exceção dos períodos de depressão - abnormal liquidation) e um mecanismo de perturbação baseado em inovações e no overshooting de expectativas de ganhos supranormais que elas causavam - independetemente do escopo tecnológico desta inovação apresentar alcance setorial ou sistêmico. É por essa razão que Perez reconhece: "Schumpeter does lay the foundations for a theory of the cyclical nature of the capitalist economy but not of long waves" (PEREZ, 1983:2, grifo nosso).

\footnotetext{
${ }^{2}$ Recentemente, reinterpretações ampliaram o alcance e o potencial do trabalho de Perez. Kattel et. al (2009) argumentam que o arcabouço dos ciclos longos baseados no PTE contribui para (i) explicar a dinâmica social e econômica do capitalismo desde a primeira Revolução Industrial; (ii) fornece as bases teóricas para uma macroeconomia evolucionária dinâmica e (iii) fundamenta as bases para uma abordagem econômica alternativa à modelagem matemática neoclássica, entendida pelos autores como excessivamente abstrata e ahistórica (KATTEL et. al, 2009:2).

${ }^{3}$ Ponto que é esclarecido em Perez (2002): o papel do capital financeiro é primordial - é ele que "introduz", ou facilita a emergência de um novo estilo tecnológico/PTE.
} 


\section{Figura 1 - O Paradigma Tecno-econômico em sua primeira versão (PEREZ, 1983)}

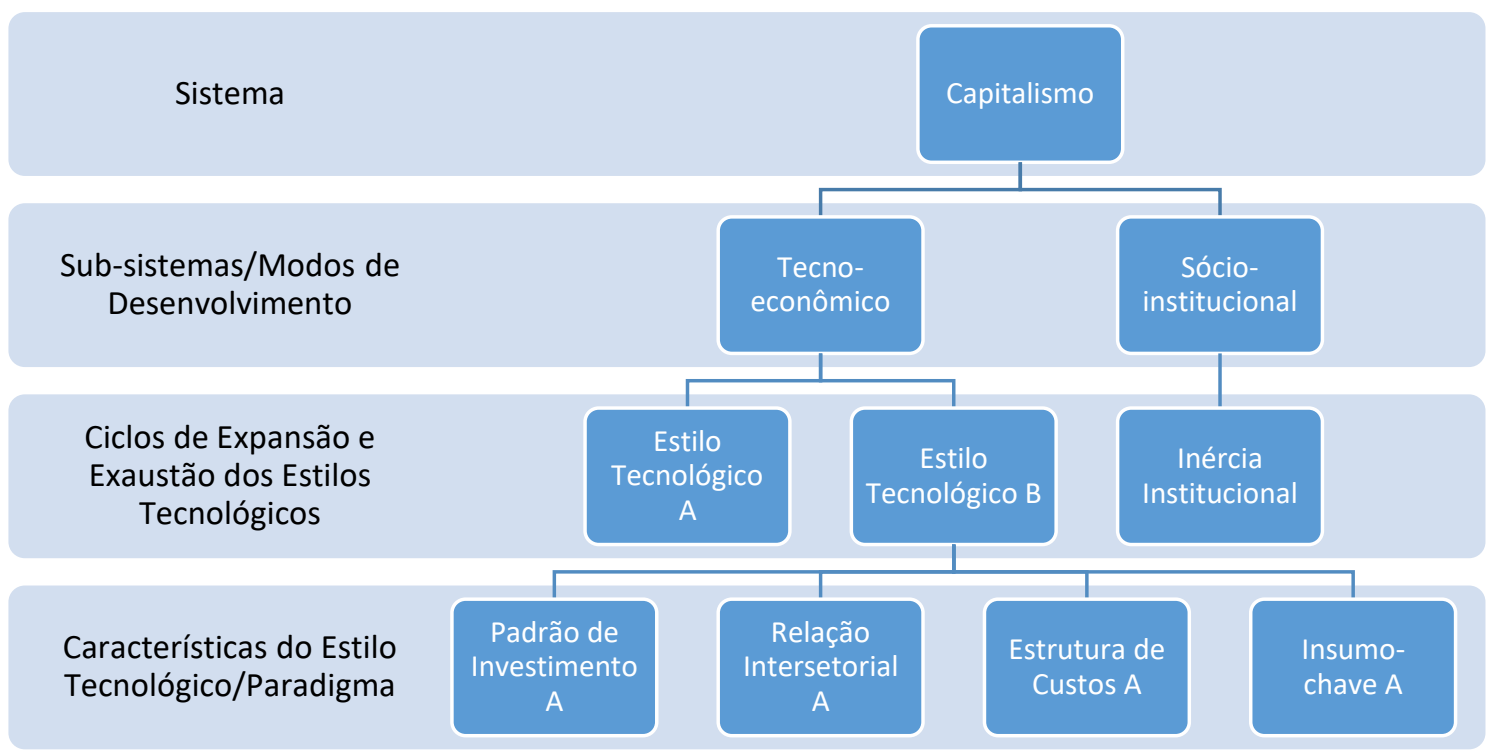

Fonte: adaptado de Perez, 1983.

Kuznets preocupa-se em compreender o mecanismo que retarda o crescimento em uma "indústria velha" à medida em que ela amadurece. Ele compartilha da visão de Schumpeter no tocante ao progresso técnico resultante das inovações: ele vem em levas, concentrado em uma indústria ou em um grupo interconectado de indústrias (SCHUMPETER, [1939] 1982). Mas Kuznets quer ir adiante e entender porque o ímpeto progressivo se perde em uma indústria com o passar do tempo e diferentes "eras" correspondem a diferentes indústrias ${ }^{4}$. Kuznets (1930) aponta para quatro elementos que surgem como potenciais fatores explicativos: (i) estagnação do progresso técnico; (ii) as indústrias de crescimento baixo retardam o crescimento das indústrias de crescimento acelerado (sendo o contrário também válido, em uma espécie de balanceamento osmótico); (iii) os fundos disponíveis para a expansão de uma indústria decrescem relativamente quando a indústria cresce; e (iv) uma indústria em um país pode ter seu crescimento retardado pela mesma indústria em um país de industrialização mais recente (KUZNETS, 1930:10 - 11).

A primeira das alternativas - a estagnação do progresso técnico - é ilustrada por uma série de relatos históricos que servem como base para a argumentação geral que, à introdução de uma inovação que revoluciona a estrutura técnica de uma indústria, seguese uma grande quantidade de aperfeiçoamentos e inovações complementares naquela indústria e nas cadeias produtivas relacionadas à ela. Com o passar do tempo, "o número de operações para serem aperfeiçoadas [...] gradualmente se exaure" (KUZNETS, 1930:31). A indústria alcança um plateau e seu produto uma forma standardizada com pouco espaço para futuros aperfeiçoamentos. Kuznets está dando forma em sua argumentação ao que seria aperfeiçoado nas décadas de 1960 e 1970: o ciclo de vida da

\footnotetext{
${ }^{4}$ Schumpeter recorre ao comportamento dos agentes econômicos para explicar porque, em uma dada indústria, ocorre este arrefecimento do ímpeto progressivo da tecnologia. A difusão motivada pela competição intercapitalista seria responsável pelo estabelecimento de um novo equilíbrio temporário. Este mecanismo, ainda que explicado em suas linhas gerais, ressalta porque uma indústria vê um momento inicial de progresso técnico se dissipar em um novo estado letárgico - mas não explica porque, historicamente, uma outra indústria toma a liderança do processo de inovação e crescimento econômico.
} 
indústria e do produto. Perez chega a aludir ao ciclo de vida das revoluções tecnológicas e ao ciclo de vida dos paradigmas tecno-econômicos (PEREZ, 2002), uma influência claramente kuznetsiana.

Em suma, o produto, a indústria ou o paradigma, se exaure por se difundir demais e então algo novo deve ocupar o seu lugar (SCHOT e KANGER, 2018). No entanto, assim como produtos não são lançados no vácuo (há sempre um mercado potencial), paradigmas tecno-econômico ou estilos tecnológicos são construídos sob instituições. A exaustão do que Perez chamou de estilo tecnológico levaria ao estabelecimento de um novo estilo - o motivo pelo qual o que era uma desaceleração da atividade econômica transmuta-se em uma crise social: instituições tornam-se anacrônicas e o um novo modo de crescimento/acumulação capitalista deve nascer a partir da extinção do estilo antigo. A influência kuznetsiana também se dá neste ponto - que talvez seja o central do pensamento de Perez - e recorremos a uma longa transcrição para ilustrar este legado:

\begin{abstract}
"Uma decorrência desta interação da mudança tecnológica e social deve ser realçada: em qualquer época o crescimento é uma questão tanto de mudança coletiva quanto de alterações estruturais. Mesmo que o impulso para o crescimento seja proporcionado por uma inovação tecnológica importante, as sociedades que a adotam precisam modificar sua estrutura institucional preexistente. Isto implica mudanças substanciais na organização da sociedade - surgimento de novas instituições e diminuição da importância das antigas" (KUZNETS, 1966 [1985]:10).
\end{abstract}

O período em que este rearranjo acontece é a crise - e ela escapa às definições economicistas em geral ao alcance daqueles que encaram o sub-sistema sócioinstitucional como um mero contexto (environment $)^{5}$.

Na figura 1, a emergência do estilo tecnológico $B$ herda as caracerísticas do estilo tecnológico anterior (A): o padrão de investimento, que determina as relações intersetoriais (e a existência de carrier, motive e induced branches); a estrutura de custos e a relação entre capital e trabalho e o insumo-chave, cuja pervasividade determinava uma best practice nos modelos de negócio no estilo tecnológico anterior. A ideia de um keyinput de Perez encontra correspondência com a noção de epochal innovations de Kuznets. Além de aportar novas características em todas estas esferas, o novo estilo tecnológico irá se chocar com a inércia institucional - a guardiã da estabilidade do paradigma que vinha dando certo até então.

Perez reconhece timidamente - e apenas em TRFC - a influência de Kuznets em sua obra (PEREZ, 2002:9-10). Como há uma relação patente da visão de épocas (ou eras) econômicas, insumos-chave ou inovações de época, exaustão de arranjos motivando a emergência de novos arranjos, interações entre o avanço tecnológico e institucional, é surpreendente que não tenha havido um reconhecimento mais forte do PTE como um desdobramento do pensamento kuznetsiano. Existe ainda mais um elemento em comum que apareceu na primeira versão do PTE, em Perez (1983): a preocupação com a dinâmica estrutural da economia em termos de ocupação e distribuição da renda, um dos temas mais explorados por Kuznets (1966 [1985]; 1989).

\footnotetext{
5 "The structural crisis thus brought about is, then, not only a process of 'creative destruction' or 'abnormal liquidation' in the economic sphere, but also in the socio-institutional" (PEREZ, 1983:3).
} 


\section{Parte II - A distribuição de renda e o PTE:duas abordagens}

Todos os elementos discutidos na primeira parte (e presentes na figura 1) permanecem nas versões posteriores que a autora apresenta do seu arcabouço (FREEMAN e PEREZ, 1988; PEREZ 2002; 2009). No entanto, um elemento do modelo de Perez (1983) recebe atenção de uma forma que não receberia dali em diante: a distribuição de renda que é resultado de um novo formato de organização da produção condicionado pelo paradigma corrente. A figura $\mathbf{2}$ apresenta as relações entre 0 PTE/estilo tecnológico, a estrutura ocupacional, a distribuição de renda e o padrão de demanda/consumo.

\section{Figura 2 - Padrões e Processos de Transformação de um Estilo Tecnológico (PTE)}

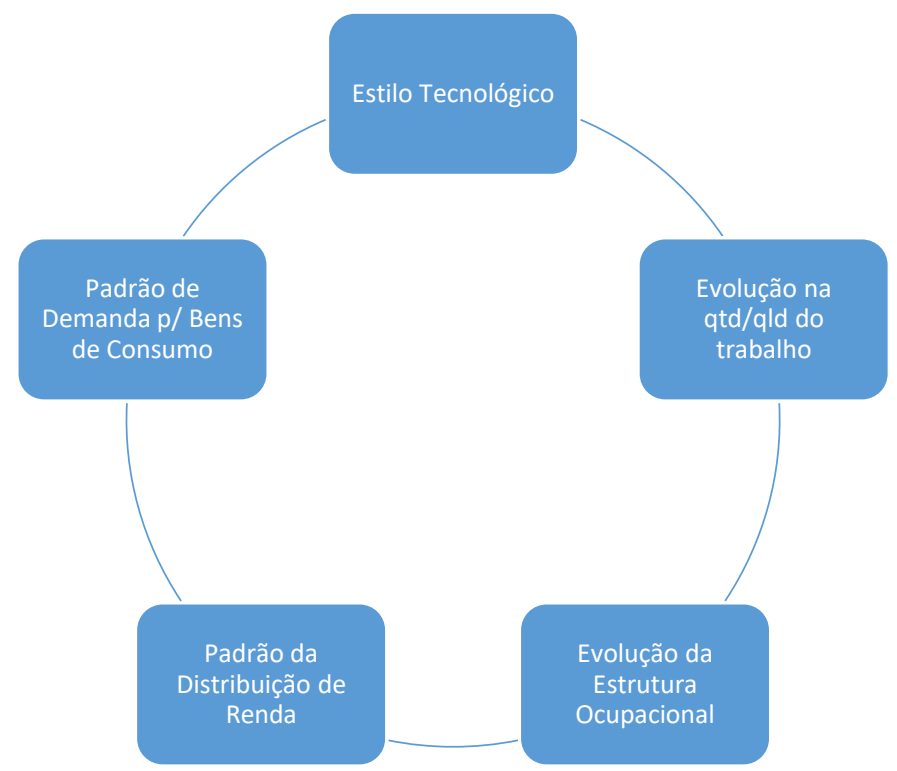

Fonte: adaptado de Perez, 1983.

O tratamento destes elementos nesta primeira proposição do conceito é muito importante. Geels (2005) ataca o PTE ao afirmar que este arcabouço negligencia o surgimento das novas tecnologias e o papel da demanda ${ }^{6}$. Ao apresentar a difusão do taylorismo, o surgimento de uma nova estrutura ocupacional com uma classe média crescente (white-collars) e o direcionamento de inovações tecnológicas para transformar produtos de luxo em produtos de consumo de massa aproveitando este mercado crescente, a crítica de Geels (2005) parece sem fundamento - ou direcionada apenas às versões mais recentes do PTE:

"[...] it is unlikely that an entrepreneur would launch a new investment to cater to a dwindling market such as cotton textiles, for instance. Instead, he might apply the new potential for productivity increase to turning a luxury good into one accessible to the growing middle layer, which is what Ford set out to do with his Model-T, and many others after him" (PEREZ, 1983:9).

Assim, a interpretação pereziana em sua origem trata da estrutura da distribuição de renda na economia como uma variável do modelo do PTE. Optamos por chamar esta

\footnotetext{
6 "Long-wave theories suffer from deterministic overtones, because there is no account of how new technologies emerge. The idea seems to be that they simply emerge from 'key factors', limits and bottlenecks in the existing TEP. This is too simple, because it ignores the variety of technologies available to solve bottlenecks" (GEELS, 2005:70).
} 
primeira abordagem de estruturante. Ela está em linha com a preocupação de Kuznets de encontrar nas modificações do padrão de demanda vetores de modificação da estrutura industrial (KUZNETS, 1966 [1985]:105). No entanto, este tratamento se perdeu nas versões subsequentes do PTE. Em Perez (1985), sua preocupação se volta para o debate das possibilidades de desenvolvimento econômico no quinto ciclo (da microeletrônica) considerando as desigualdades internacionais, o papel das multinacionais $\mathrm{e}$ as possibilidades neste novo ciclo para os países em desenvolvimento.

Em Freeman e Perez (1988) a questão central é evidenciar as lacunas da teoria pós-keynesiana (ou neo-keynesiana) com relação à mudança tecnológica de longo prazo. Uma tipologia de inovações é proposta: inovações incrementais, radicais, sistemas tecnológicos e paradigmas tecno-econômicos. Os autores utilizam os PTEs para confrontar as mudanças técnicas de amplo alcance com as expectativas de investimento dos agentes privados. Em crises que não envolvem a transição de PTE, os postulados keynesianos podem funcionar. Quando a mudança de PTE está envolvida, o envolvimento estatal deve se adaptar: é preciso se engajar na reestruturação das instituições que conformarão as novas best practices sob as características do novo paradigma. Em outras palavras, a política keynesiana de estímulo - monetário ou produtivo - à economia em fases recessivas não será suficiente para promover a retomada econômica quando um processo de mismatch entre o sistema tecno-econômico e o sócioinstitucional estiver em curso. E o engajamento na construção de novas instituições adequadas ao PTE das tecnologias de informação e comunicações deveria ser supranacional (FREEMAN e PEREZ, 1988).

A questão da desigualdade e da estrutura ocupacional não é tratada, ainda que mencionada tangencialmente. Um dos efeitos da mudança de PTE seria "a new skill profile in the labour force, affecting both quality and quantity of labour and corresponding patterns of income distribution"(FREEMAN e PEREZ, 1988:18). Sobre esta questão, os autores ainda afirmam: "The skill profile associated with the new techno-economic paradigm appears to change from the concentration on middle-range craft and supervisory skills to increasingly high - and low-range qualifications" (FREEMAN e PEREZ, 1988:19). Apesar de em linha com a abordagem estruturante, o tema não é explorado.

Finalmente, em Perez (2002), o arcabouço do PTE passa por uma ampla reformulação ${ }^{7}$ e o tratamento da desigualdade de renda reaparece, ainda que diluído ao longo dos elementos do modelo e de forma diferente daquela apresentada em Perez (1983). Nesta obra, Carlota Perez produz uma elegante síntese combinando a tradição schumpeteriana (e kuznetsiana, como argumentamos) com a tradição minskyana de desequilíbrios financeiros. Ela explora o papel central da esfera financeira na transição dos PTE. O capital financeiro é o catalisador da mudança estrutural: sem ele, o tecido produtivo tende a manter-se inerte, ou a modificar-se mais lentamente. A autora divide cada PTE em duas fases com duas etapas cada uma ${ }^{8}$, além de especificar a natureza de cada ponto entre uma etapa e outra (ver quadro 1 e figura 3). A figura 3 ilustra o arcabouço analítico aperfeiçoado. A primeira fase do PTE seria a Instalação (Installation), composto pelas etapas de irrupção e frenesi. A irrupção convive com o fim do PTE anterior e por isso mesmo ocorre em nichos, poucos setores da economia (ou, utilizando a terceira categoria de inovação de Freeman e Perez (1988), em poucos sistemas tecnológicos). Aos poucos, estes setores demonstram uma capacidade de obter

\footnotetext{
7 O termo estilos tecnológicos (technological stlyle) é abandonado e Perez passa a usar apenas a denominação Paradigmas Tecno-econômicos.

${ }^{8}$ Para tanto, a crítica de Tylecote (1992) de que haveria ao menos dois tipos de crises, certamente contribuiu.
} 
lucros acima da média e o capital financeiro torna-se seu mais enfático promotor: este ponto marca a revolução tecnológica. A ânsia do capital financeiro por expandir a mesma taxa de retorno para outros setores/indústrias criará as bases para que as novas práticas e as novas tecnologias - associadas a novos modelos de negócio - se difundam. Na fase do frenesi, o capital financeiro é o escudo dos novos modelos contra a resistência daqueles ainda fundamentados no PTE anterior. A liderança do capital financeiro é a mola propulsora (que em Perez (1983) era um sujeito oculto) e também o cadafalso do novo PTE: ao promovê-lo sem o zelo de uma geração de valor sustentada que o capital produtivo teria (fosse este autônomo neste interím), inevitavelmente ocorrem apostas em setores insustentáveis ou inadequados ao novo PTE. Assim, a fase de frenesi acaba abruptamente por meio de uma crise - que pode ser uma bolha, várias bolhas menores, ou uma recessão suavizada.

Esta descrição é parcialmente coerente com a própria visão schumpeteriana (1939) da fase de expansão do ciclo de negócios: as perturbações causadas por inovações levariam ao overshooting de expectativas dos agentes. Naturalmente, o sistema corrigiria seus excessos por meio de uma tendência de retorno ao "equilíbrio". Perez, no entanto, não apoia-se no instrumental neoclássico e por isso não recorre a nenhum conceito de equilíbrio: é a real e historicamente documentada explosão das bolhas de ativos que promove a correção dos excessos conduzidos prima facie pelo capital financeiro. A esta correção de rumos, Perez chama de ponto de inflexão (turning point).

Ele encerra a primeira fase de transição para o novo PTE e dá início a segunda: o Estabelecimento (Deployment). Esta fase tem duas principais características: (i) o capital financeiro baixa a guarda após o estouro da bolha e permite que o capital produtivo e outros atores participem das decisões relativas ao novo PTE, e (ii) o impacto da crise, somado à relevância dos novos setores baseados no novo PTE, finalmente convencem agentes econômicos e atores políticos de que uma nova regulamentação é necessária. Assim se inicia a reformulação sócio-institucional, harmonizando as necessidades do novo PTE com as instituições e abrindo caminho para um período de intenso crescimento econômico: é a etapa de sinergia que traz consigo a era de ouro e a face de justiça social do capitalismo. A última etapa do PTE é a maturidade, na qual o impulso de crescimento começa a perder fôlego e o capital financeiro novamente começa sua busca por novos modelos de negócio e novos setores com maior potencial de geração de valor, processo que gestará o próximo paradigma. Esta última etapa concentra a essência do pensamento de Kuznets - do limite natural do crescimento das indústrias e sua tendência a exaustão com o pensamento de Minsky - de que a estabilidade prolongada contém as sementes da própria instabilidade, devido ao apetite por aumentar a razão risco/retorno do capital financeiro.. 


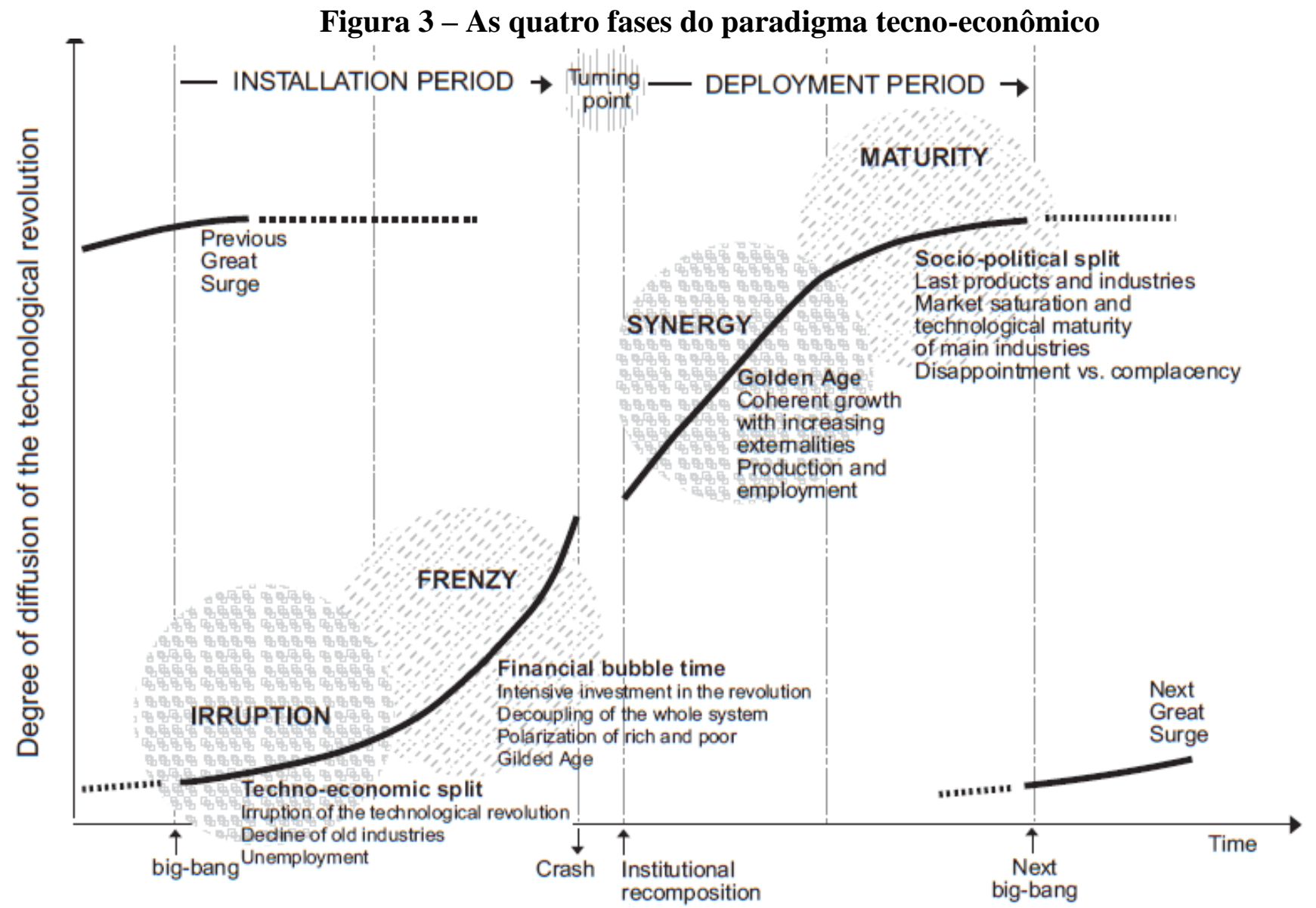

Fonte: Perez, 2002. 
Há inúmeras quetões associadas a esta rica síntese do movimento do sistema capitalista. Vamos nos concentrar no tratamento da questão da equidade. Perez argumenta que a primeira fase do PTE - Instalação - é marcada pela acentuação da desigualdade de renda. Isto já aparece na introdução de TRFC: "For each technological revolution, that time-lag is characterized by strong divergence in the rates of growth of industries, countries and regions as well as a worsening of the trends in income distribution that had previously prevailed." (PEREZ, 2002:xvii, grifo nosso). O "time-lag" seria o tempo que toma para se passar da primeira para a segunda fase do PTE. Em outras palavras, a primeira fase, de Instalação do paradigma, deve ser marcada por aumento da desigualdade de renda.

\section{Quadro 1 - Definições conceituais em TRFC}

- Revolução Tecnológica: "A technological revolution can be defined as a powerful and highly visible cluster of new and dynamic technologies, products and industries, capable of bringing about an upheaval in the whole fabric of the economy and of propel-ling a long-term upsurge of development" (PEREZ, 2002:8);

- Paradigma Tecno-econômico (I):"A techno-economic paradigm is, then, a bestpractice model made up of a set of all-pervasive generic technological and organizational principles, which represent the most effective way of applying a particular technological revolution and of using it for modernizing and rejuvenating the whole of the economy" (PEREZ, 2002:15);

- Paradigma Tecno-econômico (II):" "A techno-economic paradigm, being a sort of mental map of best-practice options, is made up as much of an understanding of actual generic technologies with nearly all-pervasive applicability as of general commonsense principles that enter the culture of the period" (PEREZ, 2002:16);

- Grande Salto de Desenvolvimento: “A great surge of development is defined here as the process by which a technological revolution and its paradigm propagate across the economy, leading to structural changes in production, distribution, communication and consumption as well as to profound and qualitative changes in society." (PEREZ, 2002:20);

- Capital Financeiro: "Thus, financial capital represents the criteria and behavior of those agents who possess wealth in the form of money or other paper assets [...] in the end, by whatever means, their purpose remains tied to having wealth in the form of money ('liquid' or quasi-liquid) and making it grow" (PEREZ, 2002:71);

- Capital Produtivo: "By contrast, the term 'production capital' embodies the motives and behaviors of those agents who generate new wealth by producing goods or performing services" (PEREZ, 2002:71)

Fonte: Perez (2002)

Em outra passagem, a autora reforça seu posicionamento de que a primeira fase veria deterioração da equidade, enquanto a segunda reverte esta tendência rumo a uma prosperidade compartilhada em alguma medida. Sobre a etapa de frenesi, ao final da primeira fase, Perez afirma: "It is at the same time - and partly for the same reason - a time of extremely unbalanced prosperity and of polarization on all fronts" (PEREZ, 2002:99). Em alguns momentos, a autora parece tratar da desigualdade desta etapa do PTE como um atributo relacionado não a indivíduos (households), mas a desigualdades intersetoriais e internacionais - um segundo tipo de desigualdade de que trata Tylecote 
(1992). De acordo com Perez, na fase de frenesi a desigualdade se aprofundaria entre "indústrias, países, regiões e firmas" (PEREZ, 2002:100).

Para compreender esta questão, é preciso fazer uma observação quanto aos limites da capacidade do arcabouço pereziano de promover uma interpretação da economia política da inovação e do progresso técnico. Perez (2002) utiliza categorias funcionais no seu esquema dinâmico: capital financeiro e capital produtivo (ver definições no quadro 1) são entendidos como tipos ideais de funções - tal qual a função do empreendedor schumpeteriano. Não entra no arcabouço a diferenciação entre capital e trabalhadores. Schot e Kanger ressaltam que o distanciamento dos grupos sociais que agem para influenciar a trajetória dos PTE é um dos pontos fracos do arcabouço (SCHOT e KANGER, 2018:1050-1). Perez assume implicitamente, portanto, que as fases em que o capital financeiro ganha autonomia e se descola do capital produtivo, são transversalmente concentradoras de renda: atingem indústrias, mas também indivíduos. Esta indiferenciação permite compreender como, logo após afirmar que a fase de frenesi leva à desigualdade entre setores, ela também afirme que "o frenesi é um tempo no qual os ricos tornam-se mais ricos, e os pobres mais pobres" (PEREZ, 2002:100, tradução própria).

No capítulo 11 de TRFC esta a maior parte das referências ao tema da concentração de renda. O capítulo trata do ponto de inflexão, que marca o fim da fase conentradora, o frenesi. Esta fase chegaria ao seu término devido a três tensões fundamentais que se exacerbam até o ponto de se tornarem insustentáveis. As tensões são (i) entre a riqueza real e fictícia, (ii) entre a demanda potencial e a capacidade de oferta dos produtos-chave do PTE e (iii) "entre os socialmente excluídos e aqueles sendo beneficiados pela bolha" (PEREZ, 2002:115). Perez explica a primeira tensão recorrendo à especulação financeira e ao que Schumpeter chamou de reckless banking (SCHUMPETER, 1939). A segunda e terceira tensão se agravam devido a intensificação da concentração de renda ${ }^{9}$.

$\mathrm{O}$ argumento de Perez gira em torno dos limites de mercado que a concentração de renda gera. $\mathrm{O}$ sucesso dos setores que iniciaram a trasição para um novo PTE gerou lucros supranormais que são capturados parcialmente pelos participantes daquele setor e parcialmente pelo capital financeiro. Como estes setores ainda são uma pequena parte do tecido econômico, há pouco transbordamento de seu crescimento. Esse crescimento robusto, porém constrangido, leva a saturação dos mercados que compram o produtochave do novo PTE (sejam automóveis no quarto PTE ou computadores no atual). Como resposta à saturação prematura do mercado, e buscando manter ou ampliar os lucros (pressionado pelo capital financeiro), o setor investe ainda mais em suas plantas para obter ganhos de escala. Isto gera a segunda tensão: a capacidade de oferta aumenta cada vez mais, mas a demanda é constrangida pela distribuição desigual da renda ${ }^{10}$. A terceira tensão é o resultado político-social do mesmo processo.

A tensão se resolve a partir da crise. O ponto de inflexão é o adestramento do capital financeiro após sua queda - e a construção de instituições compatíveis com

\footnotetext{
9 "The other two structural tensions stem from the same basic cause: the whole frenzy phenomenon is, at bottom, a huge process of income redistribution in favor of those directly or indirectly involved in the casino, which funds the massive process of creative destruction in the economy" (PEREZ, 2002:116).

${ }^{10}$ E Perez ainda sublinha a incapacidade de se superar o obstáculo de saturação dos mercados via políticas econômicas padrão de estímulo à demanda efetiva compreendida no agregado: "even if the quantity of money out there equals the value of production, if it is not in the right hands, it will not guarantee that markets will clear" (PEREZ, 2002:116).
} 
aqueles setores nascentes e prósperos é uma guinada em direção ao crescimento sustentado pela difusão do PTE. Nesta segunda fase, o crescimento é pautado pelo capital financeiro comedido, que responde às necessidades do capital produtivo; pela onda de crescimento em mais setores, que se conectaram à "nova economia" na esteira da reforma institucional; pela distribuição mais equânime dos ganhos advindos do progresso técnico. Esta fase de sinergia será liderada pelo capital produtivo e, tendo aprendido a lição da saturação dos mercados, buscará ampliá-los. Uma das formas para tanto é a distribuição progressiva da renda. Assim começa uma "era de ouro" compartilhada (PEREZ, 2002:133).

Assim, desenha-se a abordagem da distribuição em TRFC: um fenomeno cíclico e determinado pelo acomplamento do capital financeiro e produtivo. Chamamos esta segunda abordagem de desigualdade pendular. Nas fases em que o acoplamento ocorre (principalmente a fase de sinergia), a prosperidade é compartilhada; nas fases em que ocorre desacoplamento, ocorre concentração de renda. Cumpre reconhecer que o nível de concentração/desconcentração aludido é transversalmente definido: atinge de grandes agregados setoriais ${ }^{11}$ à indivíduos. Ao mesmo tempo, Perez deixa de dar atenção à conexão estrutura ocupacional do PTE e distribuição de renda - conforme a abordagem estruturante precedente (PEREZ, 1983). O trabalho, portanto, deixa de receber atenção, ao menos explicitamente, e o esquema dinâmico move-se quase que independente dele, alternando entre suas funções produtivas e financeiras, mas sempre sob a égide do capital.

\section{Parte III - Dados preliminares para uma interpretação do PTE atual}

Optamos por apresentar os dados apenas para os Estados Unidos. O recorte dos dados brutos é de 1913 a 2014, o que encompassa todo o quarto ciclo do PTE da produçao em massa e cinquenta anos do quinto ciclo, do PTE da microeletrônica e das TICs. O gráfico 1 corresponde a renda (antes de impostos) do percentil de renda mais alta com relação ao total. Em outras palavras, ele mostra quanto da renda total é capturada pelo $1 \%$ mais afluente da população. Os pontos vermelhos no gráfico correspondem, da direita para a esquerda, o início do ponto de inflexão do $4^{\circ}$ PTE, o ano de 1928 , em que o total da renda capturado pelo $1 \%$ de maior renda atinge sua máxima nesta série $(21,4 \%)$; o segundo ponto $(11,1 \%)$ marca o fim da fase de prosperidade e o início de um novo PTE (1971); o terceiro ponto, em 2008, marca o ponto de inflexão do atual PTE, em que novamente a renda apropriada pelo $1 \%$ superior $(19,5 \%)$ aproxima-se de seu recorde dos anos de 1920.

Os fatos estilizados apresentados por Perez (2002) parecem estar de acordo com estes dados. De fato, após a crise de 1929, ocorre um decrescimento progressivo do total da renda nacional apropriada pelo $1 \%$ superior. Resulados semelhantes são obtidos realizando o mesmo exercício para o decil superior. A tendência também parece coerente com os fatos estilizados. O gráfico mais completo, com todos os decis, traça um cenário coerente com o preconizado pela primeira fase do PTE, concentradora de renda. Do início do PTE atual em diante (1971 - ), é possível observar no gráfico 2 a renda do percentil superior da população (1\% da população) ultrapassando a renda dos $50 \%$ inferior da população nos EUA ao longo da década de 1990.

\footnotetext{
${ }^{11} \mathrm{O}$ desequilibrio setorial fica registrado na passagem "For those pursuing the accumulation of wealth, the higher profits possible in the financial sphere discourage direct engagement in productive activities, except those related to the newest and most dynamic technologies" (PEREZ, 2002:111). As fases do ciclo afetariam o equilíbrio setorial em termos de atratividade de investimentos. O setor que mais cresce recebe mais aportes, os outros crescem menos e sofrem mais para obter investimentos.
} 
Gráfico 1 - Renda antes de impostos do percentil mais rico nos EUA - 1913 a 2014

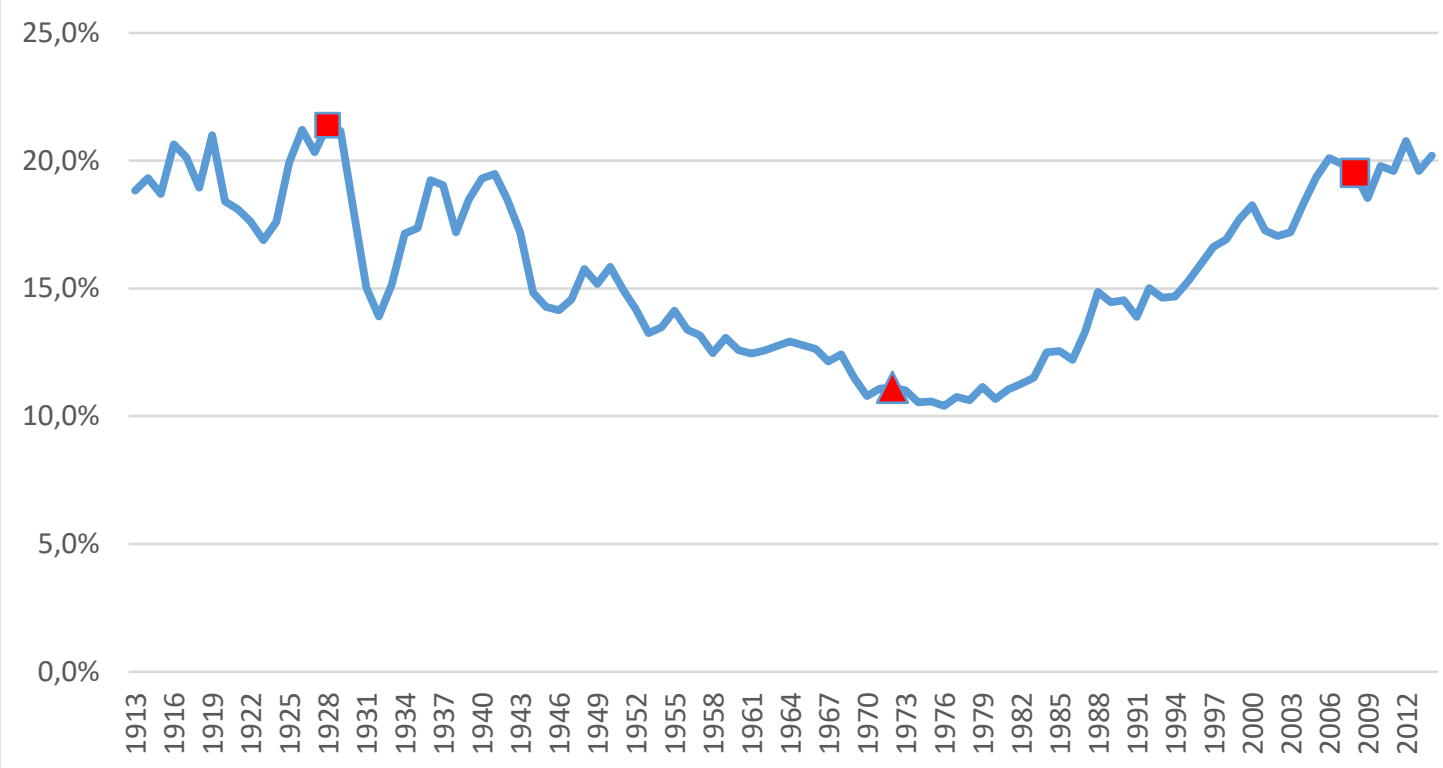

Fonte: WID.

Outro ponto interessante do gráfico 2 é a pauperização da classe média norteamericana. De mais de $46 \%$ da renda nacional, esta fração da população passou a capturar menos de $40 \%$. Ao mesmo tempo, o primeiro decil da população amealhou frações crescente de 1970 em diante: de iniciais $35 \%$ para mais de $47 \%$.

\section{Gráfico 2 - Todos os percentis da população norte-americana e a fração da renda nacional pré-taxação de cada grupo, 1971 - 2014.}

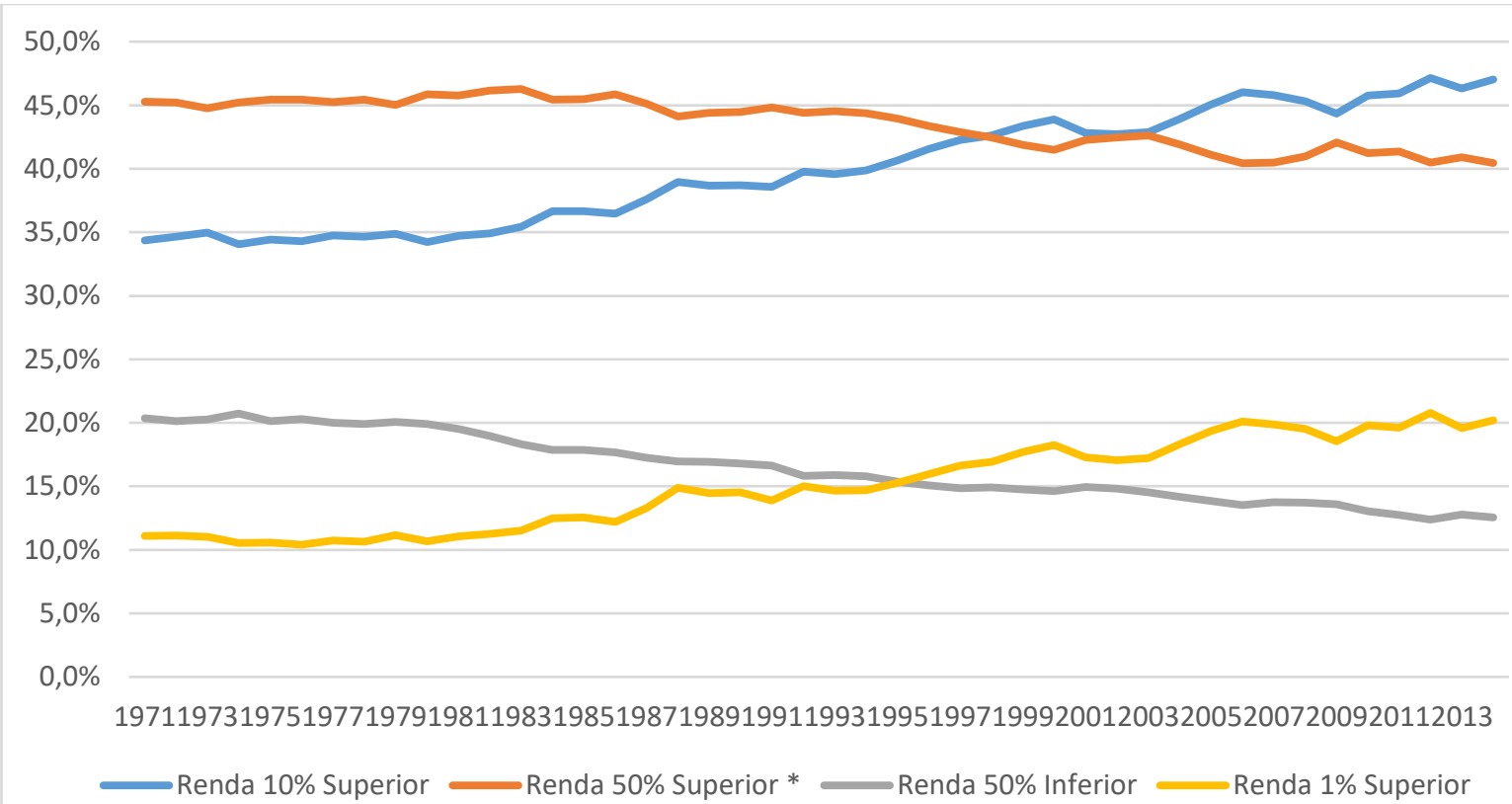

Fonte: WID. * Se refere a renda dos $40 \%$ da população que estão entre os $50 \%$ inferior e os $10 \%$ superior - uma aproximação da classe média.

No entanto, enquanto o ponto de inflexão do penúltimo PTE localizado nos EUA compreende o período entre os anos 1929-43, o ponto de inflexão do atual PTE é menos 
claro. Estaríamos atravessando este momento desde a bolha da internet em 2000 e a grande crise financeira de 2007-8 (SCHOT e KANGER, 2018:1047). O que chama atenção é que, mesmo após as duas crises (PEREZ, 2009b), não há reversão desta tendência ${ }^{12}$, como seria de se esperar. Podemos descartar, portanto, a hipótese da desigualdade pendular? É possível colocar o problema na forma de duas hipóteses (não necessariamente excludentes):

H1: a hipotese da desigualdade pendular é correta, mas fatores tais como (i) a gestão das crises, (ii) atalhos à exaustão de mercados impediram as reformas necessárias. Em algum momento, os subterfúgios utilizados pelo capital produtivo para contornar a exaustão de mercados internos e pelo capital financeiro para guiar a regulamentação a seu favor, se esgotarão e a reforma será inevitável;.

H2: a estrutura ocupacional e distributiva gestada no início do PTE (1970-80) sobrepõem-se a eventuais flutuações pendulares da renda. Neste caso, o PTE atual pode ser muito menos equitativo na esfera distributiva do que o PTE anterior. As reformas já teriam sido realizadas e estaríamos assistindo o desdobramento de um PTE que evoluiu para tornar funcional a concentração da renda.

Exploremos H1: a dupla crise (PEREZ, 2009b) não ensejou a reforma institucional porque, apesar delas, não ocorreu a acumulação de uma massa crítica com força suficiente para se contrapor as forças de manutenção da institucionalidade vigente. Schot e Kanger (2018) comentam que, para Perez, este fato está relacionado a propagaçao da ideologia neoliberal - que de alguma forma, poderia conter o ímpeto redistributivo a qualquer custo. Vimos que a concentração de renda cumpre, por dois canais, o papel de forçar a reforma institucional. A revolta social seria um deles. Supostamente ela catalisaria uma agenda de reformas institucionais visando controlar a ciranda financeira e empoderar o capital produtivo. O momento histórico, em especial a conjuntura política internacional, parece não ter grandes semelhanças com a pressão por reformas que acabou em Bretton Woods e no New Deal. A insatisfação popular em função da desigualdade de renda exite, mas sob os governos não paira a ameaça de um sistema alternativo ao sistema capitalista como havia durante as décadas de 1940-50, momento de recomposição institucional do PTE anterior ${ }^{13}$. A etapa hiper-financeirizada global atual não enfrenta nenhuma ameaça global capaz de levar à mesa os estadistas de todo o mundo para uma reforma concertada. Considerando o anti-globalismo que toma forma, o contrário acontece: respostas nacionais/nacionalistas parecem emergir, na esperança de que serão capazes de contornar as dificuldades imposas pela globalização do capital. Agindo coletivamente, seria incerto se os estados-nação conseguiriam domar o capital financeiro; agindo unilateralmente, não são grandes as chances de que consigam reverter a dominância financeira instalada em quase todos os cantos do globo ${ }^{14}$.

O segundo canal de ação da concentração de renda sobre o status quo institucional também apresenta problemas. Ainda não ocorreu a exaustão dos mercados para os produtos chave do PTE atual (setor de microeletrônica). E isto pode ser resultado do

\footnotetext{
${ }^{12}$ The impact of the financial crisis is visible on top-income shares, which exhibit a marked declined after 2007 Novel data suggest that top incomes have either recovered their shares or are progressively recovering them (ALVAREDO, et. al, 2018:69).

13 “There is no structured ideology or program to confront them; no positive sum political design has been put on the table offering to intensify wealth creation in ways that will reverse the income polarization trends and compensate the negative effects of globalization on the weakest"(PEREZ, 2013:21).

${ }^{14}$ Ainda que Perez enfatize em quase todos os seus trabalhos, desde 1983, que a criação das instituições adequadas/ideais para este paradigma deveria ser global
} 
movimento de expansão geográfica do capitalismo - e a inclusão das economias russa e chinesa ao longo da decada de 1990/2000 (PEREZ, 2009b:790-791). Perez (2002) havia inclusive previsto a possibilidade de haver mais de uma solução para a exaustão dos mercados: a economia de guerra era um exemplo; o estado redistribuidor das economias capitalistas do ocidente pós-II guerra, outro. A transnacionalização e globalização dos mercados pode ser considerarda a via encontrada atualmente para contornar o problema da exaustão dos mercados domésticos ${ }^{15}$; em outras palavras, apesar do capital financeiro dar mostras dramáticas de seu desalinhamento, o capital produtivo ainda encontra meandros para se reproduzir.

No entanto, uma pequena demonstração do padrão de exportações norteamericanas pode revelar que esta é uma saída com seus próprios problemas. A figura 4 traz as exportações líquidas norte-americanas de produtos microeletrônicos entre $1996 \mathrm{e}$ 2016. O produto que contabilizou pela maior parte das exportações líquidas foram os circuitos integrados - o key-input do PTE atual de acordo com Perez (1985; 2002). Nos últimos cinco anos ,a fração dos circuitos integrados no total de exportações líquidas sofreu uma acentuada queda (de um pico de US\$22, 5 em 2006 para US\$4,96 em 2016).

\section{Figura 4 - Exportações líquidas de produtos microeletrônicos dos EUA, a valores correntes (bilhões de dólares de 2016), de 1995 a 2016}

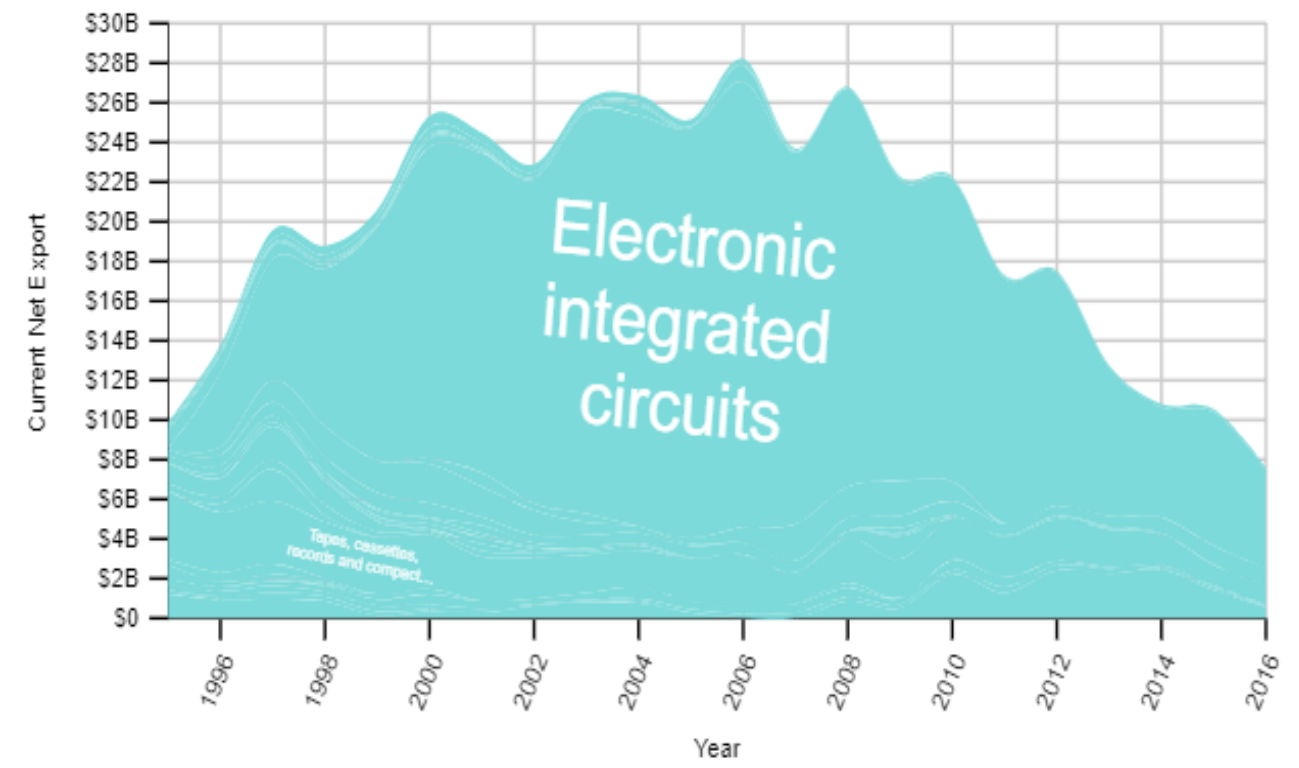

Fonte: Atlas of Economic Complexity (http://atlas.cid.harvard.edu/)

O problema é: a exaustão da alternativa dos mercados internacionais não vem sido enfrentada por meio da promoção da ampliação dos mercados domésticos (via distribuição da renda/riqueza); ela ensejou uma guerra comercial (SWANSON, 2018) que pode por fim ao livre mercado e é uma ameaça ao sistema OMC. O PTE atual, portanto,

\footnotetext{
15 Outro fator fornece alternativas a uma demanda constrangida pela alta concentração de renda: a hipersegmentação de mercados (PEREZ, 2010). A flexibilização produtiva permitida pela robotização levou ao movimento de commoditização de quase todos os produtos manufaturados - inclusive aqueles relacionados ao PTE atual - e ao mesmo tempo, à customização em massa. Isso permite que empresas explorem diferentes nichos de mercado. Em outras palavras, criaram-se novos espaços de produção, comercialização e de inovação. É possível, para uma empresa que fabrica smartphones, por exemplo, explorar o potencial da demanda dos $50 \%$ da população de menor renda nos países em desenvolvimento.
} 
parece estar munido de várias ferramentas capazes de contornar a concentração de renda, sem resolvê-la. A própria estrutura em que este PTE evoluiu parece fundamentar-se na concentração e alimentar-se dela.

Com isso, chegamos a H2. Existe ainda uma outra questão que Perez não tocou. A renda pode ser desagregada em renda do capital e renda do trabalho. E embora não seja surpresa que a renda do capital dos percentis ou decis superiores da população venha crescendo, chama atenção o fato de que os cinco decis inferiores da população (p0p50) recentemente passaram a ter renda de capital positiva - e principalmente, que a fração de toda a renda do trabalho do percentil e do decil superior aumentam consistentemente desde a década de 1960.

Talvez a financeirização não teria consequências sociais tão trágicas caso a estrutura ocupacional tivesse permitido uma divisão da renda do trabalho mais equânime. O que se vê é que ela está sendo cada vez mais concentrada, desde antes do início do PTE atual. O percentil superior (p99p100 - os famosos 1\%) capturavam apenas 6,3\% da renda do trabalho em 1966; em 2014, ele se apropria de 14\%. O decil superior (p90p100) amealhava pouco mais de $27 \%$ da renda do trabalho em 1966 - total que passa para mais de $40 \%$ em 2014.

\section{Gráfico 4 - Renda do trabalho antes de impostos por decil/percentil da população norte-americana, de 1966 a 2014.}

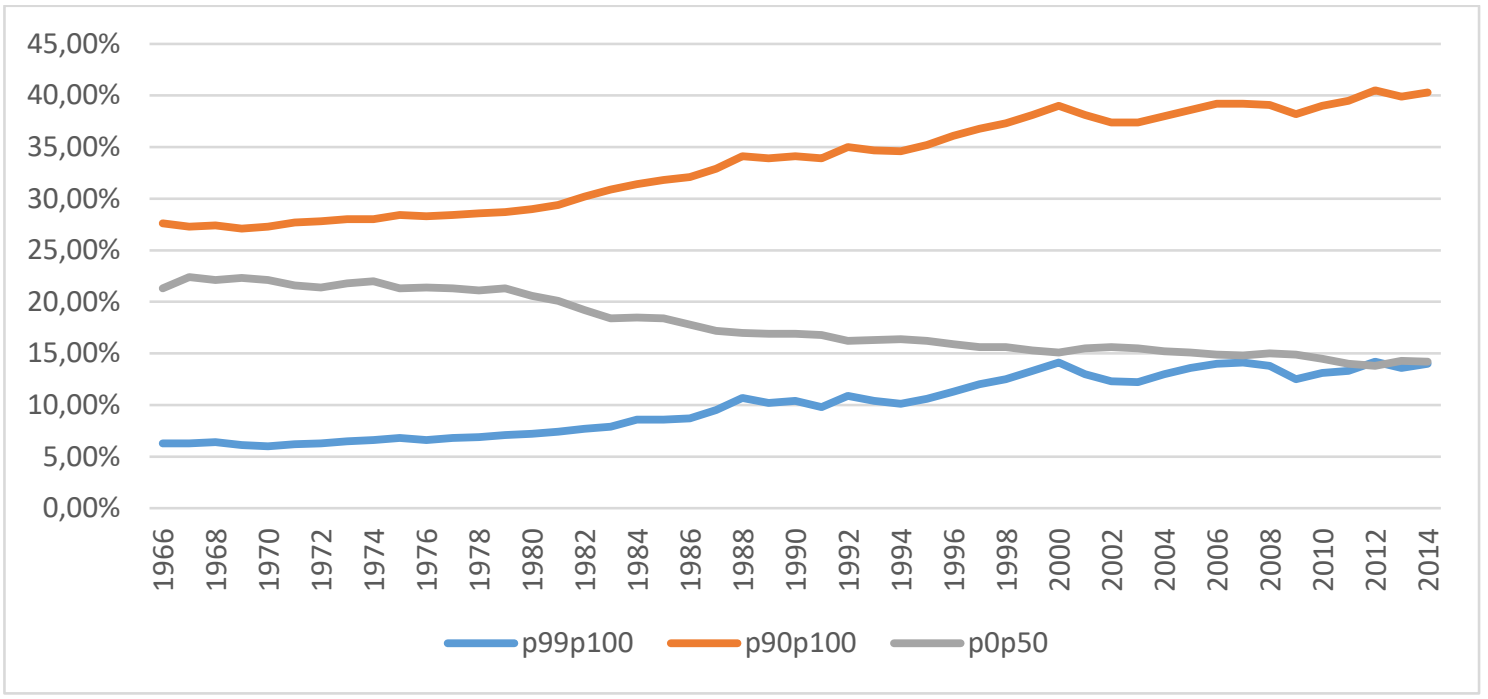

Fonte: WID.

Buscar formas alternativas de renda para os cinco decis inferiores pode ser uma necessidade, afinal o gráfico 4 demonstra como o decil superior e o percentil superior da população se apropriaram de uma fração cada vez maior da renda do trabalho. O gráfico 5 mostra a renda de capital do primeiro decil, dos cinco últimos decis e do primeiro percentil antes de impostos. É possível observar que em 2013, pela primeira vez na série, a renda de capital dos cinco decis inferiores torna-se positiva - ou seja, a metade menos favorecida da população começou a se beneficiar de rendas de capital, denotando uma tímida, porém gradual, rentierização da sociedade norte-americana. A classe mais baixa está, pela primeira vez, sobrevivendo em função de ganhos de capital! Mas como isso foi possível? 


\section{Gráfico 5 - Renda de capital antes de impostos por decil/percentil da população norte-americana, de 1966 a 2014.}

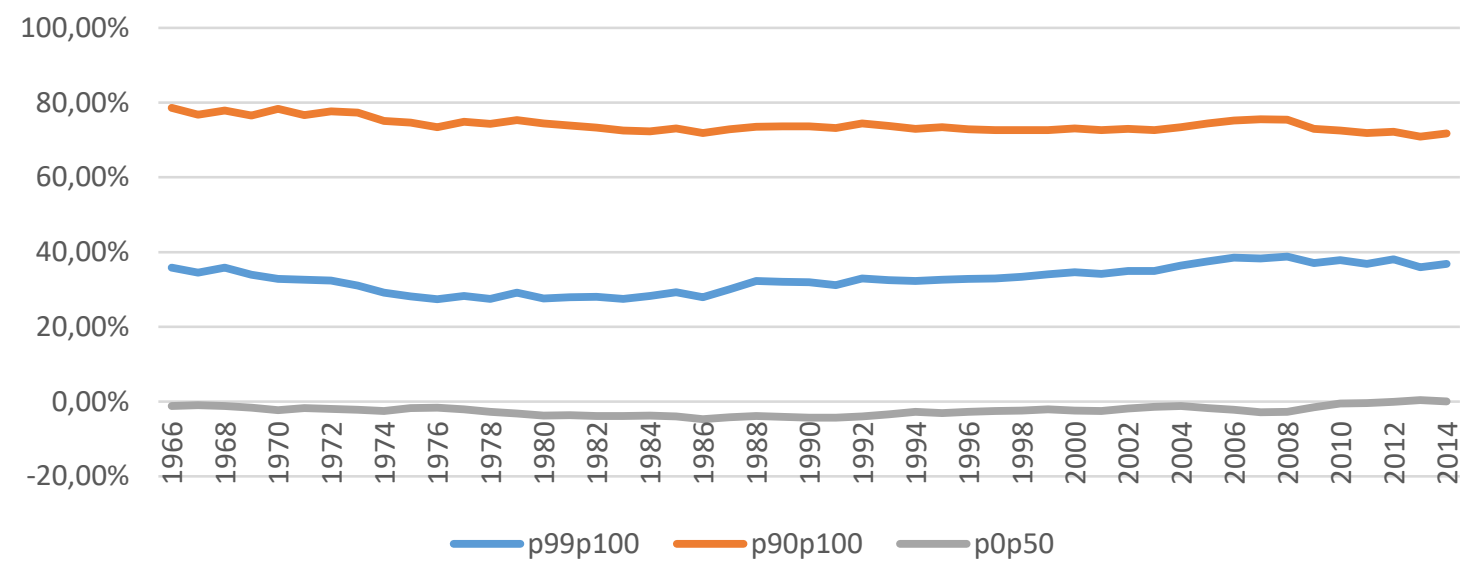

Fonte: WID.

A figura 5 pode nos ajudar a compreender esta dinâmica. Extraída do World Inequality Report, a figura 5 demonstra a evolução da fração de toda a riqueza (ativos como valores imobiliários líquidos, pensões, paricipações corporativas e investimentos financeiros) detida pelo que seria a classe média norte-americana (p0p90 - isto é, excluindo-se os $10 \%$ do topo). Do total da riqueza, $16 \%$ estava nas mãos desse grupo no início dos anos 1930. Em meados de 1980, ao final do PTE fordista-taylorista, a classe média viu-se com quase $40 \%$ da riqueza nacional, muito graças a acumulação de riqueza imobiliária e de pensões (ALVAREDO et. al, 2018). De 1980 até os dias atuais, a tendência é de diminuição da fração da riqueza nas mãos da classe média - e, portanto, de concentração da riqueza no topo da hierarquia social.

Figura 5 - Composição da fração da riqueza detida pelos $90 \%$ inferiores nos EUA, $1917-2012$

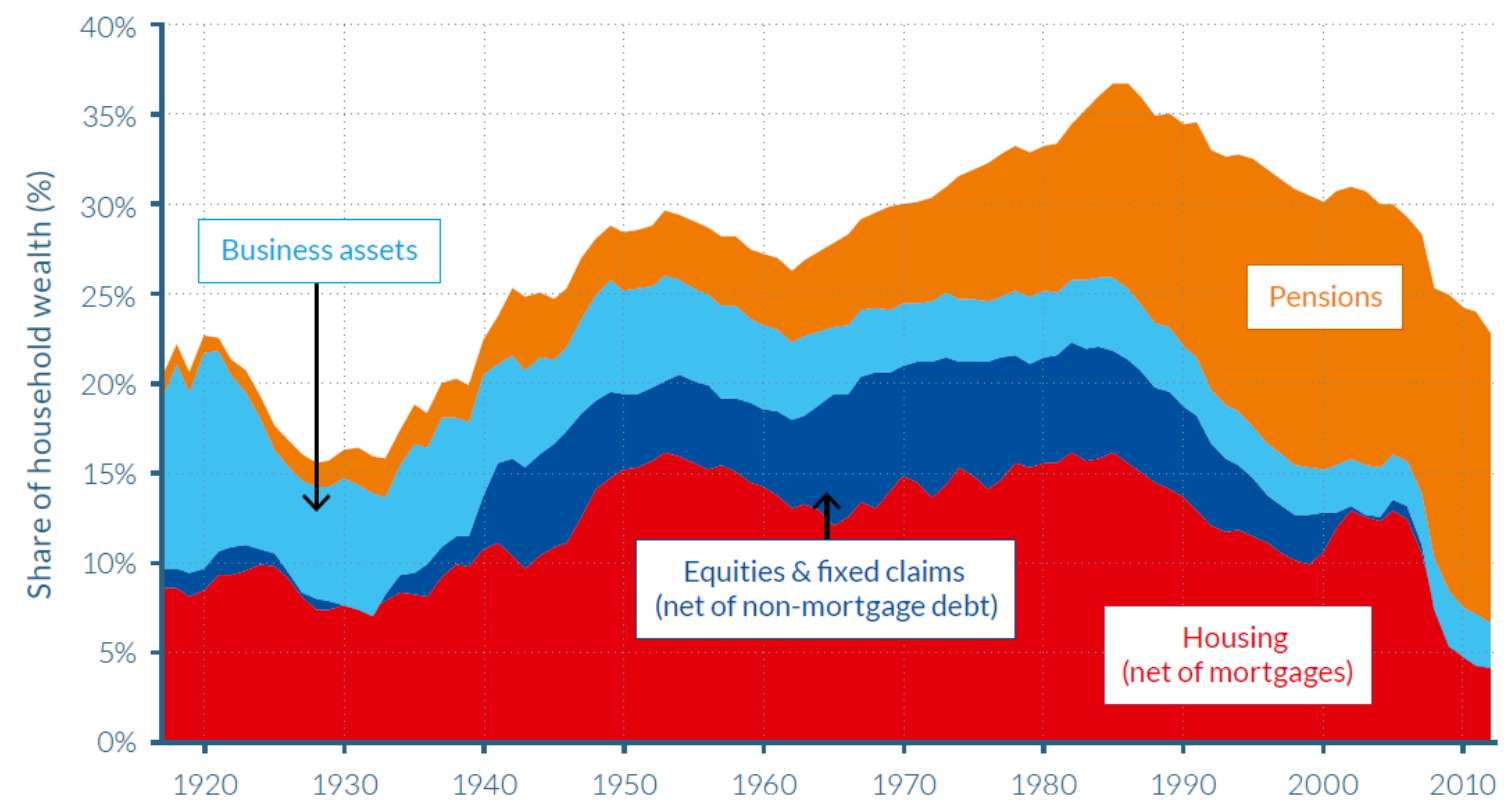

Fonte: extraído de Alvaredo (2018). 
A queda na fração da riqueza atribuída aos $90 \%$ inferiores da população norteamericana está relacionada, entre outros fatores, com a acentuação da desigualdade de renda e com a desigualdade nas taxas de poupança - no longo prazo, ambas afetam a distribuição de riqueza (ALVAREDO, 2018:217). No entanto, o que queremos ressaltar com a figura 5 é: a classe média nos EUA dos anos 2000, especialmente até antes da crise de 2008, estava montada em uma pilha de ativos acumulados no PTE anterior e convivia com uma estrutura ocupacional cada vez menos amigável do ponto de vista da renda corrente.

Esta estrutura ocupacional pouco amigável é resumida por Lazonick (2013) como o desaparecimento dos empregos da classe média. Este autor relaciona o PTE anterior com a best practice de "retain and reinvest": as empresas retinham seus lucros e reinvestiam em seus funcionários para um crescimento sustentado; o PTE atual seria pautado pela best-practice de "downsize and distribute". Este novo paradigma levou a reestruturação industrial "in ways that have eroded the quantity of jobs that offer stable employment and good pay in the American economy" (LAZONICK, 2002:4). Um estudo conduzido por Spence e Hlatshwayo $(2011 ; 2012)$ concluiu que uma crise estrutural de empregos está posta nos EUA. Empregos em tradables dos anos 1990 em diante reduziram-se e a realocação destes profissionais para non-tradables (especialmente setor público e área de saúde) tem limites fiscais e de produtividade:

"The evolution of the U.S. economy supports the notion of there being a long-term structural challenge with respect to the quantity and quality of employment opportunities in the United States. A related set of challenges concerns the income distribution; almost all incremental employment has occurred in the nontradable sector, which has experienced much slower growth in value added per employee. Because that number is highly correlated with income, it goes a long way to explain the stagnation of wages across large segments of the workforce" (SPENCE e HLATSHWAYO, 2011)

E ainda, "The most educated, who work in the highly compensated jobs of the tradable and nontradable sectors, have high and rising incomes and interesting and challenging employment opportunities, domestically and abroad. Many of the middleincome group, however, are seeing employment options narrow and incomes stagnate" (SPENCE e HLATSHWAYO, 2012:730). Um empresário que observasse para o estadoda-arte da tecnologia do PTE atual - (consideramos o grande conjunto das TICs) e para o panorama apresentado da estrutura ocupacional e distributiva, tomaria que decisão de investimento? Ele provavelmente apostaria na economia on-demand.

Os modelos de negócio originais dos últimos anos são capitaneados por empresas como Uber e AirBnb. Alguns analistas associaram estas empresas como parte de um movimento de economia compartilhada. Elas parecem se encaixar, no entanto, mais como inovações induzidas pela escassez (scarcity-based innovation) (SRINIVAS e SUTZ, 2008). A própria história relatada pelo fundador da AirBnb demonstra como a companhia 
surgiu: sem renda para arcar com os gastos do seu aluguel, ele decidiu alugar quartos e camas ociosos para obter uma renda ${ }^{16}$. Esta narrativa é coerente com os seguintes pontos:

- a transformação da estrutura ocupacional nos EUA - modulada por uma nova ideologia gerencial e um novo modelo organizacional - que levou ao downsizing de firmas e a relocalização de plantas em países com custo da mão de obra mais baixo;

- a consequente necessidade de se buscar fontes alternativas de renda nos estratos inferiores (gráfico 4/gráfico 5) já que os empregos de renda média se extnguiam e a distribuição da renda do trabalho concentrava-se cada ver mais no estrato superior (gráfico 4);

- a disponibilidade de riqueza acumulada no paradigma anterior (figura 5);

- a conjunção de todos estes fatores com a disponibilidade de tecnologias baseadas em plataformas e redes.

Nenhum laboratório, nenhum departamento de $\mathrm{P} \& \mathrm{D}$ esta por trás deste novo modelo: somente a necessidade de renda, derivada de uma estrutura ocupacional que comprimiu a classe média norte-americana e aumentou o número de pessoas sem ocupação permanente e sem renda ${ }^{17}$. Argumentamos, portanto, que a emergência do autoempresário (ou self-employed), a alardeada inadequação das leis trabalhistas (BELLACE, 2018), gig/sharing economy (SUNDARARAJAN, 2016), a emergência do precariado (STANDING, 2011) são todos elementos pertencentes ao paradigma atual condicionados pela estrutura ocupacional e distributiva gestada nos anos 1970/80. A desigualdade distributiva, por este prisma (H2), não é uma fase do PTE que se reverterá após reformas institucionais adequadas; a desigualdade esta no próprio DNA deste paradigma, em sua ideologia gerencial, em suas best-practices, em suma, em sua estrutura do trabalho e de distribuição dos frutos do mesmo que deu origem a trajetórias tecnológicas originais e sui generis.

Para concluir, o PTE do consumo em massa e do fordismo, Perez reconhece, foi dentre todos o que teve maior força do capital produtivo na fase de crescimento compartilhado $^{18}$. O atual PTE dá indícios de que pode ser o seu antípoda. Mesmo na sua segunda fase, após as reformas institucionais, o capital financeiro ainda poderá desfrutar de grande poder e o padrão de desigualdade de renda pode não se reverter na intensidade desejada para uma prosperidade compartilhada. Por esta razão, ao invés do tratamento da desigualdade pendular, parece ser mais interessante recuperar a abordagem estruturante esboçada em Perez (1983) e explorada indiretamente em Perez (2010). A grande ideia contida em Perez (1983) está resumida na passagem:

\footnotetext{
16 “Chesky's vision for AirBnb was modest when he began. "The motivation for starting AirBnb was to be able to pay our rent in October 2007'"' (SUNDARARAJAN, 2016).

${ }^{17}$ A este aspecto das novas formas de inovação, Perez chama de "grassroots entrepreneurship". Ela afirma que seriam precisos esquemas de financiamento para viabilizar os novos negócios deste mercado super segmentado e especializado (PEREZ, 2013:18). O que para nós falta na análise de Perez é o reconhecimento de que esta nova forma de "empreendedorismo" emerge da pauperização das massas, baseia-se predominantemente em negócios de baixa intensidade tecnológica e baixa produtividade.

18 "As in any marriage, the question of which of the partners is in control is resolved depending on the relative power of each. It will also depend on the specific circumstances, the nature of the triumphant paradigm and the unique political scene of the time [...] the post-Second World War synergy phase in the USA has been the clearest historical case of production capital being in control. This was so much so that, for a while, the stock market was hardly present as a dynamic force" (PEREZ, 2002:128).
} 


\begin{abstract}
"the diffusion of a new form of organization of production requiring a new skill profile, translates into changes in income distribution which, in turn, affect the pattern of demand, signalling to producers the general characteristics of the new types of products which would both cater to the growing markets and be capable of being produced with the new technological style through which the process becomes a gradually accelerating feedback loop" (PEREZ, 1983:9).
\end{abstract}

Esta abordagem enfatiza os feedbacks entre os sub-sistemas tecno-econômicos e sócio-institucionais e coloca uma alteração na estrutura ocupacional associada a um novo modelo organizacional como um dos principais dínamos da transformação sistêmica. No fim das contas, as tecnologias-chave, os insumos-chave, etc., podem vir a reboque do novo padrão de demanda criado pela interação daqueles elementos. E Perez faz a ligação entre esta estrutura ocupacional, seu padrão de distribuição de renda e as trajetórias de inovação e progresso técnico induzidas por aquela configuração. Certamente, o reconhecimento de que assim se deu no quarto ciclo não significa que sempre será assim. Mas, no mínimo, requer que a estrutura ocupacional e a distribuição da renda sejam elementos centrais na investigação do direcionamento dos PTE.

A linha de raciocínio baseada em $\mathbf{H 2}$ nos leva a questionar se, de fato, o PTE atual já não se realizou em todo o seu potencial - e que, talvez, a realização deste potencial não seja capaz de contrarrestar as tendências concentradoras de renda induzidas pela estrutura ocupacional que se desenvolveu dos anos 1970 em diante. Preferimos seguir Schot e Kanger (2018) que consideram a possibilidade de vários PTE disputarem primazia no momento de transição do velho para o novo e conjecturar que ainda há espaço para uma mudança de direção do que foi esboçado até aqui. Também há conforto em pensar que depois de um PTE sempre segue-se um outro. Por enquanto, uma frase atribuida a W. Gibson resume bastante bem o PTE atual encarado da perspectiva de H2: "The future is already here - it's just not evenly distributed".

\title{
Referências Bibliográficas
}

ALVAREDO, F., (2018). World Inequality Report 2018, World Inequality Lab.

BELLACE, J., (2018). Back to the future : workplace relations and labour law in the 21 st century in the Asia Pacific context, Asia Pacific Journal of Human Resources. BOWLES, S., (2010). The new economics of inequality and redistribution. Cambridge University Press.

CEPAL, (2018). The Inefficiency of Inequality. Summary (LC/SES.37/4), Santiago.

FREEMAN, C., PEREZ, C., (1988). 'Structural Crises of Adjustment: Business Cycles and Investment Behavior', in Dosi et al. (eds), pp. 38-66.

GEELS, (2005). Technological Transitions and System Innovations: A CoEvolutionary and Socio-Technical Analysis. Cheltenhan, UK: Edward Elgar.

KATTEL, R., DRECHSLER, W., REINERT, E., (2009). Introduction: Carlota Perez and Evolutionary Economics, in Drechsler, Kattel, Reinert (eds.), Techno-Economic Paradigms: Essays in Honour of Carlota Perez. London, New York, Delhi: Anthem Press. KUZNETS, S. (1930). Secular Movements in Production and Prices: Their Nature and their Bearing upon Cyclical Fluctuations. Boston: Houghton Mifflin.

KUZNETS, S., (1966[1985]). Crescimento Econômico Moderno, Abril Cultural. LAZONICK, W., (2002). Introduction: Corporate Resource Allocation and Employment Opportunities in the United States in LAZONICK, W., O'SULLIVAN, M., (eds.), Corporate Governance and Sustainable Prosperity, p. 1 - 11. Palgrave.

LAZONICK, W., (2013). The Financialization of the U.S. Corporation : What Has Been Lost, and How It Can Be Regained, Seattle University Law Review, 36, p. 857 - 909. 
PEREZ, C., (1983). 'Structural Change and the Assimilation of New Technologies in the Economic and Social Systems', Futures, Vol. 15, No. 5, pp. 357-75.

PEREZ, C., (1985). Microelectronics, Long Waves and World Structural Change: New Perspectives for Developing Countries, World Development, Vol. 13, No. 3, pp. 44163.

PEREZ, C., (2002). Technological Revolutions and Financial Capital: The Dynamics of Bubbles and Golden Ages. Edward Elgar, Cheltenham.

PEREZ, C., (2009). Technological revolutions and techno-economic paradigms, Cambridge Journal of Economics, 34:1, p. 185 - 202.

PEREZ, C., (2009b). The double bubble at the turn of the century: Technological roots and structural implications, Cambridge Journal of Economics, 33, special issue, p. 779 $-805$.

PEREZ, C., (2010). The financial crisis and the future of innovation: A view of technical change with the aid of history. WP: February 2010. Working Papers in Technology Governance and Economic Dynamics, No. 28, Tallinn University of Technology, Estonia, and The Other Canon Foundation, Norway.

PEREZ, C., (2013). Unleashing a golden age after the financial collapse: Drawing lessons from history in Environmental Innovations and Societal Transitions, Vol. 6, March, pp. 9-23.

PEREZ, C., (2016). Capitalism, Technology and a Green Global Golden Age: The Role of History in Helping to Shape the Future" in Mazzucato, M., e Jacobs, M. (eds.), Rethinking Capitalism: Economics and Policy for Sustainable and Inclusive Growth. Wiley-Blackwell.

SCHOT, J., KANGER, L., (2018). Deep transitions: Emergence, acceleration, stabilization and directionality, Research Policy, 47, p. $1045-1059$.

SCHUMPETER, J., ([1939]1982). Business cycles: a theoretical, historical and statistical analysis of the capitalist process. New York, NY: McGraw-Hill.

SPENCE, M., HLATSHWAYO, S., (2011). The evolving structure of the American economy and the employment challenge, Council on Foreign Relations, Working Paper. SPENCE, M., HLATSHWAYO, S., (2012). The evolving structure of the American economy and the employment challenge. Comparative Economic Studies, 54:4, p. 703 $-738$.

SRNIVAS, SUTZ, (2008). Developing countries and innovation: Searching for a new analytical approach, Technology in Society, 30:2, p. 129 - 140.

STANDING, G., (2011). The Precariat: the new dangerous class. Bloomsbury Academic.

STIGLITZ, J., (2016). Inequality and Economic Growth in Mazzucato, M., e Jacobs, M. (eds.), Rethinking Capitalism: Economics and Policy for Sustainable and Inclusive Growth. Wiley-Blackwell.

SUNDARARAJAN, A., (2016). The Sharing Economy: the end of employment and the rise of crowd-based capitalism. MIT Press.

SWANSON, A., (2018). White House to Impose Metal Tariffs on E.U., Canada and Mexico, The New York Times, disponível em < https://www.nytimes.com/2018/05/31/us/politics/trump-aluminum-steel-tariffs.html >, último acesso em 09/06/2018.

TYLECOTE, A., (1992). The Long Wave in the World Economy: The Current Crisis in Historical Perspective, London and New York: Routledge.

UNCTAD, (2018). Corporate Rent-Seeking, Market Power and Inequality: time for a multilateral trust buster? Policy Brief, n. 66. 